\title{
DESENVOLVIMENTO DE MUDAS DE BROMÉLIA (Neoregelia cruenta (R. Graham) L. B. Smith) CULTIVADAS EM DIFERENTES SUBSTRATOS E ADUBAÇÃO FOLIAR
}

\author{
Development of plantlets of bromeliad (Neoregelia cruenta) cultivated \\ in different substrates and leaf fertilizers
}

\author{
Clarissa Alves Ferreira1, Patrícia Duarte de Oliveira Paiva², Tatiana Michlovská Rodrigues ${ }^{3}$, \\ Dayana Portes Ramos ${ }^{4}$, Janice Guedes de Carvalho ${ }^{5}$, Renato Paiva ${ }^{6}$
}

\begin{abstract}
RESUMO
As bromélias apresentam formas exóticas com uma grande diversidade de cores e de flores, constituindo importantes espécies para uso em paisagismo e floricultura. Em consequiência disto, são muito comercializadas. Porém, parte das plantas que se encontram no mercado, ainda são provenientes do extrativismo. Esta situação é também reflexo do pequeno número de informações sobre técnicas de propagação e cultivo. Uma das limitações é o desconhecimento do tipo de substrato e adubação adequados ao cultivo destas espécies. Assim, o objetivo deste trabalho foi avaliar o crescimento de bromélias do Neoregelia cruenta, cultivadas em diferentes substratos e adubações foliares através da altura, do número de folhas, da matéria fresca e seca, da parte aérea e das raízes. As mudas utilizadas foram provenientes de cultura de tecidos. Após um período de pré-aclimatização, foram transplantadas para estufa sem nebulização. Os substratos foram constituídos da mistura de diferentes proporções de solo, areia, casca de arroz carbonizada e por um substrato comercial à base de vermiculita. Aos substratos foi aplicada adubação foliar, combinando uréia e sacarose, em intervalos de quinze dias. Os resultados obtidos mostraram que as interações entre os substratos, dose de sacarose e de uréia, não afetaram a altura das mudas e o número de folhas. $\mathrm{O}$ uso de sacarose também não influenciou o desenvolvimento das mudas. $\mathrm{O}$ substrato comercial à base de vermiculita, independente da aplicação de adubação foliar, proporcionou maior altura das mudas e número de folhas. A aplicação de uréia apresentou efeito linear crescente durante o período avaliado.
\end{abstract}

Termos para indexação: Bromeliaceae, uréia, sacarose.

\section{ABSTRACT}

The bromeliads present exotic forms with a great variety of colors and flowers and are considered as important species used in landscape design and floriculture. As a consequence, these species are well commercialized. However, a part of these plants still come from natural extraction. This situation is also a consequence of the reduced technical information regarding its propagation and development. One of the limitations is the lack of knowledge regarding the type of substrate and adequate fertilizer for its cultivation. The objective of this study was to evaluate the development of Neoregelia cultivated in different substrates and leaf fertilizers through the variables height, leaf number and fresh and dry matter of shoots and roots. The plantlets used were produced by tissue culture. After a period of pre-acclimatization, the plantlets were transferred to a green house without nebulization. The substrates consisted of different proportions of soil, sand and carbonized rice husk and a commercial substrate composed of vermiculite. Leaf fertilizers were applied to the substrates combining urea and sucrose in intervals of fifteen days. The results showed that the interactions of the substrates and the sucrose and urea dosages had no effect on height and leaf number. The use of sucrose also showed no influence on plant development. The commercial substrate composed of vermiculite, independent of the leaf fertilizer application, showed the best results for plant height and leaf number. The use of urea presented a crescent linear effect during the evaluated period.

Index terms: Bromeliaceae, urea, sucrose.

(Recebido em 27 de abril de 2004 e aprovado em 27 de setembro de 2005)

\section{INTRODUÇÃO}

A família Bromeliceae possui plantas que impressionam por suas formas exóticas, pela gama de cores e variedades de suas flores. Têm grande valor para arranjos em vasos de interior e, também, ocupam sempre lugar de destaque em projetos paisagísticos (MENDONÇA, 2002). A valorização do uso das bromélias, leva a acreditar no

\footnotetext{
Engenheira Agrônoma, Mestranda em Fitotecnia pelo Departamento de Agricultura/DAG da Universidade Federal de Lavras/UFLA - Cx. P. 3037 37200-000 - Lavras/MG - clarissaaf04@yahoo.com.br

'Engenheira Agrônoma, Dra., Professora no Departamento de Agricultura/DAG da Universidade Federal de Lavras/UFLA - Cx. P. 3037 - $37200-000$ Lavras/MG - pdolivei@ufla.br

${ }^{3}$ Engenheira Agrônoma, Dra. em Fitotecnia - UFU - Instituto de Ciências Agrárias - Av. Amazonas s/n, Bloco 2E, Pós-Graduação - Bairro Umuarama Campus - Umuarama - 38400-902 - Uberlândia/MG - tatiana mrodrigues@yahoo.com.br

${ }^{4}$ Engenheira Agrônoma, Mestranda em Horticultura - FCA/UNESP - Fazenda Lageado - R. José Barbosa de Barros, 1780 - Botucatu/SP pitchagro@yahoo.com.br

${ }^{5}$ Engenheira Agrônoma, Dra., Professora no Departamento de Ciência do Solo/DCS da Universidade Federal de Lavras/UFLA - Cx. P. 3037 37200-000 - Lavras/MG - janicegc@ufla.br

${ }^{6}$ Engenheiro Agrônomo, Dr., Professor no Departamento de Biologia/DBI da Universidade Federal de Lavras/UFLA- Cx. P. 3037 - $37200-000$ Lavras/MG - renpaiva@ufla.br
} 
potencial brasileiro de se tornar um grande exportador mundial dessas plantas, tão procuradas em outros continentes.

Muitas espécies comercializadas são provenientes do extrativismo, pois não há muitas informações técnicas de propagação e cultivo deste grupo de plantas. Sabe-se que as bromélias podem ser propagadas de forma sexuada ou assexuada. A propagação sexual envolve a formação de sementes, das quais se pode obter grande quantidade de mudas (RAUTH, 1990). Porém, apresenta algumas limitações, como a demora na maturação das sementes e a necessidade de 3 a 8 anos para o florescimento, dependendo da espécie, e ainda a possibilidade de variação genética (SPURR et al., 1977).

A propagação vegetativa é realizada através da remoção de brotações laterais da planta- mãe, que ocorrem em pequeno número, geralmente no período de senescência. Estas brotações são facilmente enraizadas (WALL, 1988).

A técnica de cultura de tecidos vem sendo muito utilizada na Floricultura, pois a multiplicação é rápida e a qualidade, a uniformidade e a quantidade de mudas produzidas são maiores que as obtidas através dos métodos convencionais (GATTI, 1992).

Na propagação de plantas através da técnica da cultura de tecidos, a aclimatização é fase crítica do processo. Apesar disso em geral, as bromélias obtidas in vitro não demonstram dificuldade quando aclimatizadas em vasos (MERCIER \& KERBAUY, 1994).

Uma das limitações para o desenvolvimento das mudas na fase de aclimatização ex vitro é a determinação do tipo de substrato a ser utilizado, devido a problemas relacionados aos efeitos sobre a translocação de água, ao sistema solo-planta-atmosfera e no estabelecimento de novo sistema radicular (SPURR \& BARNES, 1973). Plantas epífitas como as bromélias exigem substratos de baixa densidade, alta permeabilidade e aeração. A presença de matéria orgânica em grande proporção no meio de cultivo pode melhorar tais características (KAMPF, 1992).

As fibras de xaxim ainda são muito utilizadas no preparo de substratos, mesmo estando em risco de extinção (ANDRADE \& DEMATTÊ, 1999). O xaxim (Dicksonia sellowiana) consta na relação das espécies e subespécies vegetais raras ou ameaçadas da Portaria Ibama 06/92, sendo sua extração ilegal considerada crime ambiental segundo o artigo 46 da Lei 9605/98, com agravante de estar ameaçada, conforme o artigo 15, alínea "q" da mesma lei (DICKSONIASELLOWIANA, 2005). Estas fibras possuem vantagens, como boa capacidade de retenção de água, boa capacidade de drenagem, $\mathrm{pH}$ ácido e razoável quantidade de nutrientes disponíveis para a planta (GONÇALVES, 1992).

Carvalho \& Coimbra (1995) avaliaram diferentes substratos (utilizando xaxim ou palha de côco) e tipos de adubação no cultivo de Vriesia fosteriana e concluíram que ambos os substratos eram muito pobres para o fornecimento de nutrientes e que o desenvolvimento das plantas ocorreu devido às adubações que foram realizadas. Takeyoshi et al. (1984), utilizando como substrato casca de arroz carbonizada, obtiveram $99 \%$ de enraizamento de estacas de Chrysanthemum morifolium Ramat cv Polaris. Carneiro (1997) utilizou com sucesso o Plantmax ${ }^{\circledR}$ na aclimatização de bromélias.

Segundo Silva et al. (2000), a pulverização de sacarose foi eficiente apenas em plantas de café despauperadas, independente da concentração de sacarose utilizada. Livramento et al. (2003) constatou que a pulverização de sacarose a $2 \%$ foi mais eficiente no aumento de produtividade em comparação com a testemunha.

Objetivou-se neste trabalho, avaliar o desenvolvimento de mudas de bromélias Neoregelia cruenta cultivadas em diferentes substratos, e com diferentes níveis de adubação com uréia associada à sacarose.

\section{MATERIAL E MÉTODOS}

O experimento foi instalado em Casa-de-vegetação do Departamento de Agricultura da Universidade Federal de Lavras, utilizando mudas de bromélias Neoregelia cruenta. As mudas foram produzidas em cultura de tecidos e apresentavam altura média de $5 \mathrm{~cm}$. Realizou-se uma pré-aclimatização, utilizando o substrato Plantmax $®$, que é um substrato comercial à base de vermiculita, numa estufa com nebulização constante, por um período de 5 semanas. Após esta fase, as mudas foram transplantadas para vasos plásticos, contendo os diferentes substratos utilizados neste estudo e mantidas em uma estufa sem nebulização. Os substratos utilizados foram: $\mathrm{S}_{1}-50 \%$ de solo $+50 \%$ de areia, $\mathrm{S}_{2}-42 \%$ de solo $+42 \%$ de areia + $16 \%$ de casca de arroz carbonizada e $\mathrm{S}_{3}-100 \%$ Plantmax ${ }^{\circledR}$, combinações baseadas no trabalho de Rodrigues, 2003. Foi realizada uma adubação básica em todas as mudas constituída de $\mathrm{N}-300 \mathrm{mg}^{-\mathrm{dm}^{-3}}$; P-200 mg.dm ${ }^{-3} \mathrm{~K}-150 \mathrm{mg} \cdot \mathrm{dm}^{-3} ; \mathrm{Ca}-75 \mathrm{mg} \cdot \mathrm{dm}^{-3} ; \mathrm{Mg}-15 \mathrm{mg} \cdot \mathrm{dm}^{-3}$; $\mathrm{S}-50 \mathrm{mg} \cdot \mathrm{dm}^{-3}$; B- $0,5 \mathrm{mg} . \mathrm{dm}^{-3}$; Cu-1,5 mg.dm ${ }^{-3}$; Fe-5 mg.dm ${ }^{-3}$; Mo-0,1mg.dm ${ }^{-3} ; \mathrm{Zn}-5 \mathrm{mg} . \mathrm{dm}^{-3}$, segundo a recomendação de Malavolta (1980). 
Nas plantas, que estavam em vasos com capacidade de $600 \mathrm{~mL}$, foi realizada adubação foliar. Foram aplicadas soluções via pulverização, constituída de todas as combinações possíveis de diferentes doses de uréia $(0 ; 1$; $2 \%)$ e de sacarose $(0 ; 0,5 ; 1 \%)$, em intervalos de quinze dias, durante 6 meses.

O delineamento experimental utilizado foi de blocos ao acaso, com 4 blocos, 2 plantas por parcela e 27 tratamentos num esquema fatorial $3 \times 3 \times 3$, com 3 doses de uréia: 0,1 e $2 \%$ combinadas com 3 doses de sacarose: 0, 0,5 e $1 \%$ e com as 3 formulações de substrato $S_{1}, S_{2}$ e $S_{3}$. As mudas foram avaliadas após 60, 120, 180, 240 e 300 dias da instalação do experimento, observando a altura e o número de folhas. Na última avaliação determinou-se também a matéria fresca e seca das raízes e da parte aérea.

Todos os dados observados foram submetidos à análise estatística utilizando o sistema SISVAR (FERREIRA, 1999).

\section{RESULTADOS E DISCUSSÕES}

Os resultados obtidos quanto à altura de mudas mostraram que as interações entre substratos, doses de sacarose e doses de uréia não tiveram efeito significativo. Para a altura de mudas, o efeito do substrato foi significativo após 180 dias da instalação do experimento, sendo as melhores alturas $(19,69 ; 20,55 ; 20,95 \mathrm{~cm}$ para 180 , 240, 300 dias, respectivamente) obtidas em plantas cultivadas no substrato Plantmax ${ }^{\circledR}$ (Figura 1).

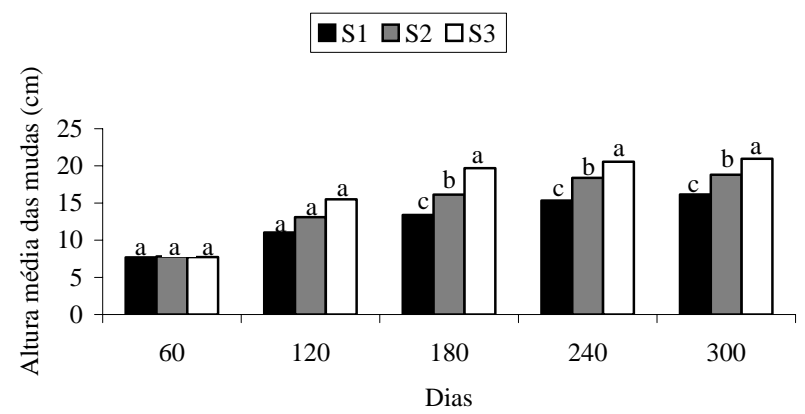

FIGURA 1 - Altura média das mudas de bromélia Neoregelia cruenta, em função dos dias de cultivo e dos diferentes substratos.

Normalmente, as plântulas oriundas de cultura de tecidos apresentam pequena taxa de crescimento e grande variação no estágio de desenvolvimento. O substrato apresenta grande importância no pegamento dessas plântulas na fase de aclimatização. Somente após os primeiros meses, a atividade metabólica das plântulas aumenta significativamente, com absorção dos nutrientes contidos no substrato (PASQUAL et al., 1997; RODRIGUES, 2003). Portanto, a escolha do substrato ideal auxilia no sucesso da produção de mudas. Neste caso, o melhor substrato foi o Plantmax $\left(\mathrm{S}_{3}\right)$, como se observa na Figura 1.

Comparando as mudas desenvolvidas in vivo com as cultivadas in vitro, estas últimas em geral, apresentamse pouco lignificadas e com sistema vascular pouco desenvolvido, estando sujeita a desordens morfológicas e fisiológicas (PASQUAL et al., 1997). Devido a este fator é necessário que as mudas se restabeleçam primeiro, justificando, assim, o início de resposta ao substrato somente aos 180 dias após a instalação do experimento.

Segundo Rodrigues (2003), mudas de bromélia imperial (Alcantarea imperialis (Carrière) Harms) apresentaram melhor crescimento no substrato constituído de $50 \%$ de terra e $50 \%$ de casca de arroz carbonizada.

Com relação à sacarose, não houve efeito significativo em nenhuma das épocas estudadas.

A uréia apresentou efeito significativo aos 150 e 210 dias da primeira aplicação da adubação foliar, ou seja, 240 e 300 dias, respectivamente da instalação do experimento. Observou-se um efeito linear em ambos os casos (Figura 2).

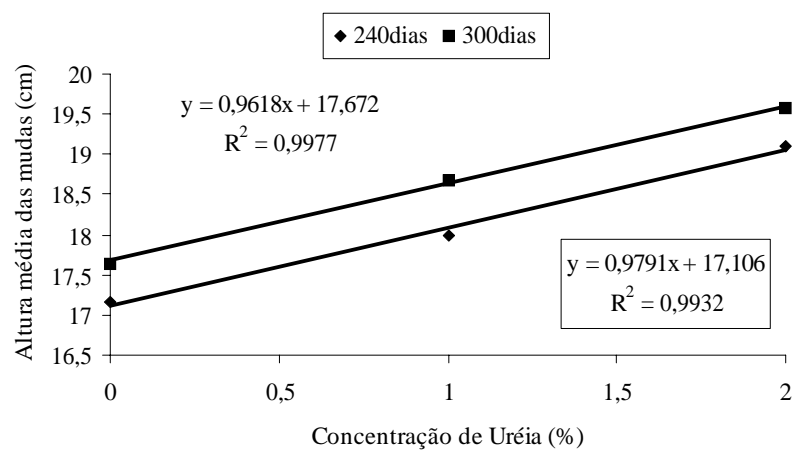

FIGURA 2 - Altura média das mudas de bromélia Neoregelia cruenta, em função das diferentes concentrações de uréia aplicadas.

Além de a uréia volatilizar facilmente (FAQUIN, 2001), o mesmo efeito morfológico e fisiológico sugerido anteriormente explica o início do efeito da uréia aos 150 dias da primeira aplicação da adubação foliar. À medida que as plântulas atingiram um pleno desenvolvimento vegetativo, começaram a responder à adubação com uréia, de forma linear crescente, como pode ser visto na Figura 2. $\mathrm{Na}$ ausência de aplicação de uréia, as plantas possuíam

Ciênc. agrotec., Lavras, v. 31, n. 3, p. 666-671, maio/jun., 2007 
altura média de 17,15 e 17,65 cm após 240 e 300 dias, respectivamente. Ao contrário com aplicação de 2,0\% de uréia, as plantas possuíam altura média de 19,11 e 19,57 cm, também após 240 e 300 dias, respectivamente. Isto pode ser explicado por ser o nitrogênio principal elemento promotor de desenvolvimento vegetativo.

Os resultados obtidos quanto ao número de folhas mostram que as interações entre substratos, doses de sacarose e de uréia também não foram significativas. Por meio da análise realizada, aos 60 dias da instalação do experimento, não houve diferença para o número de folhas formadas nas plantas cultivadas nas três formulações de substratos. A partir dos 120 dias, o substrato Plantmax ${ }^{\circledR}$ $\left(\mathrm{S}_{3}\right)$ proporcionou um maior número de folhas em comparação com os outros tipos de substratos (Figura 3).

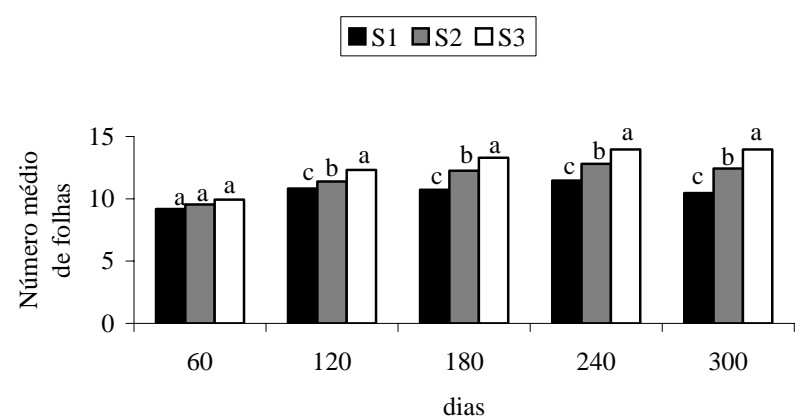

FIGURA 3 - Número médio de folhas formadas em bromélias Neoregelia cruenta cultivadas em diferentes substratos, em função da idade das mudas.

O tratamento com sacarose apresentou significância aos 30 dias da primeira aplicação da adubação foliar, ou seja, 120 dias da instalação do experimento. $\mathrm{Na}$ Figura 4 pode ser observado o efeito quadrático.

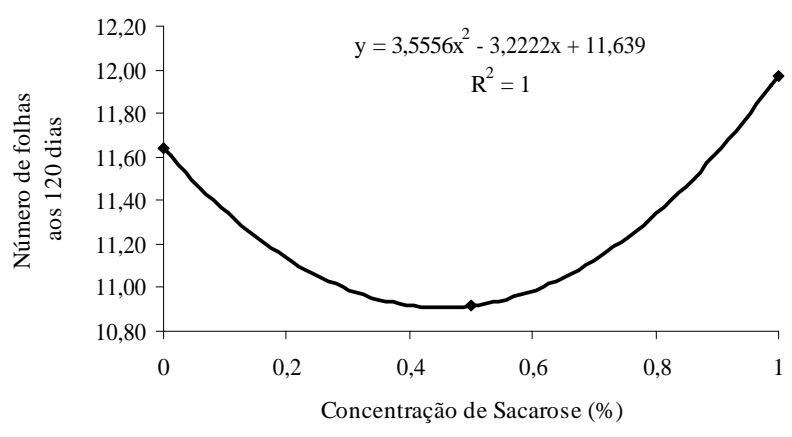

FIGURA 4 - Número de folhas das mudas de bromélia Neoregelia cruenta após 120 dias, em função das diferentes concentrações de sacarose aplicada
Geralmente as plântulas provenientes de cultura de tecidos apresentam baixa taxa de crescimento e grande variação no estágio de desenvolvimento. Para o pegamento das plântulas, a escolha de um substrato ideal é de grande importância para as mesmas na fase de aclimatização, pois a atividade metabólica das plântulas tem aumento significativo após os primeiros meses, fazendo então uso da absorção dos nutrientes contidos no substrato. A fonte de carboidrato no meio de cultura se apresenta de fácil assimilação, permitindo que o mecanismo metabólico da plântula seja heterotrófico (KOZAI, 1991). Com isso os órgãos das plântulas possuem função metabólica incompleta.

A aclimatização é um processo em que há estímulo para a planta retornar à função metabólica original. Então, nesta fase, a suplementação com a sacarose é importante para o fornecimento de cadeia carbônica, em comparação pela deficiente capacidade fotossintética das plântulas. A significância da sacarose aos 30 dias pode ser devido a este fato. Após esta fase de adaptação, o uso da sacarose não proporcionou efeito significativo.

Com relação à uréia, esta só apresentou efeito significativo aos 210 dias da primeira aplicação de adubação foliar, ou seja, aos 300 dias da instalação do experimento. $\mathrm{Na}$ Figura 5, seu efeito linear crescente pode ser visualizado.

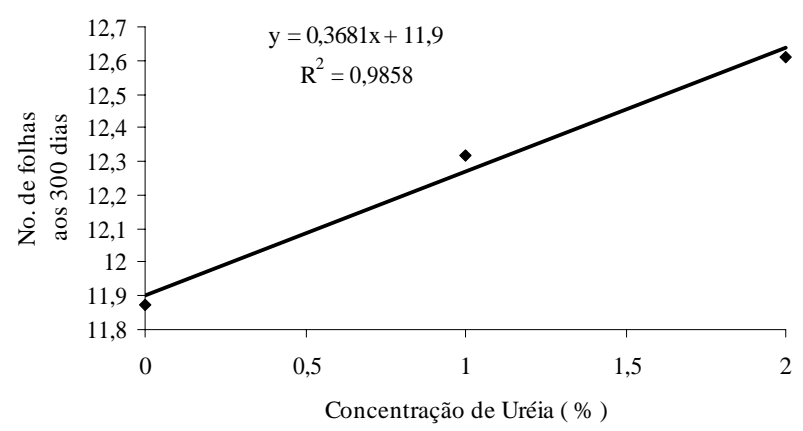

FIGURA 5 - Número de folhas das mudas de bromélia Neoregelia cruenta após 300 dias, em função das concentrações de uréia aplicada.

À medida que as plântulas alcançam pleno desenvolvimento vegetativo, começam a responder melhor à adubação com uréia, de forma linear crescente, por ser o nitrogênio o principal elemento promotor de desenvolvimento vegetativo, como pode ser visto na Figura 5. Uma outra explicação para o efeito da uréia se manifestar apenas aos 300 dias, pode ser devida ao tempo que a plântula demanda para utilizar o nitrogênio para 
síntese de aminoácidos e proteínas. Uma das razões pela qual o efeito da adubação com uréia, se manifestou mais precocemente na altura das mudas, em relação ao número de folhas, se deve ao fato de que esta última característica morfológica é secundária no desenvolvimento vegetal (FAQUIN, 2001).

$\mathrm{O}$ resultado obtido em relação à matéria fresca e seca da parte aérea da muda (Figura 6), confirma ser o Plantmax ${ }^{\circledR} \quad\left(\mathrm{S}_{3}\right) \quad$ o melhor substrato para $\mathrm{o}$ desenvolvimento aéreo da planta, seguido pelas formulações $42 \%$ de terra $+42 \%$ de areia $+16 \%$ de casca de arroz carbonizada $\left(\mathrm{S}_{2}\right)$ e depois pela $50 \%$ de terra $+50 \%$ de areia $\left(\mathrm{S}_{1}\right)$.

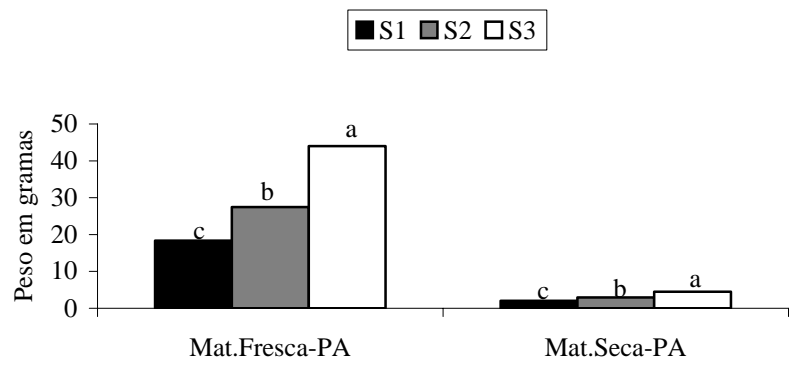

FIGURA 6 - Peso de matéria fresca e seca da parte aérea de bromélias Neoregelia cruenta, em função dos diferentes substratos de cultivo.

Já nos resultados obtidos em relação à matéria fresca e seca da raiz da muda, os melhores substratos foram a formulação $42 \%$ de terra $+42 \%$ de areia $+16 \%$ de casca de arroz carbonizada e o Plantmax ${ }^{\circledR}$, e o pior foi a formulação $50 \%$ de terra $+50 \%$ de areia como mostra a Figura 7.

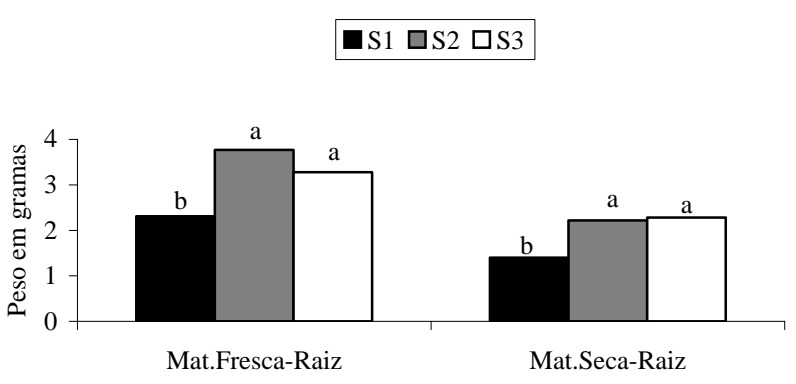

FIGURA 7 - Peso de matéria fresca e seca da raiz de bromélias Neoregelia cruenta em função dos diferentes substratos de cultivo.
Quanto à uréia, houve efeito significativo linear crescente, tanto para a matéria fresca e seca da raiz, como observado na Figura 8. Esse fato se deve à mobilidade do nitrogênio na planta (FAQUIN, 2001). Não foi observado nenhum efeito da uréia na matéria fresca e seca da parte aérea das mudas.

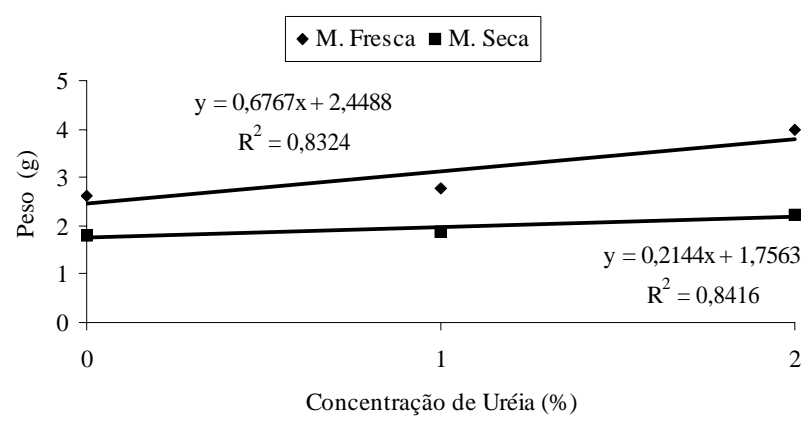

FIGURA 8 - Peso da matéria fresca e seca da raiz das mudas de bromélia Neoregelia cruenta, em função das diferentes concentrações de uréia aplicada.

\section{CONCLUSÕES}

Neste experimento pode ser observado que o melhor substrato para o desenvolvimento de mudas de bromélia Neoregelia cruenta após o período de aclimatização foi o Plantmax ${ }^{\circledR}$ e a concentração adequada de uréia, via pulverização manual, para o melhor desenvolvimento vegetativo das mudas foi a de $2 \%$, tendo efeito somente a partir de 240 dias da instalação do experimento. A aplicação foliar de sacarose na concentração de $1 \%$ até os 120 dias do plantio é importante para obter um maior número de folhas nas mudas.

\section{REFERÊNCIAS BIBLIOGRÁFICAS}

ANDRADE, F. S. A. de; DEMATTÊ, M. E. S. P. Estudo sobre produção e comercialização de bromélias nas regiões Sul e Sudeste do Brasil. Revista Brasileira de Horticultura Ornamental, Campinas, v. 5, n. 2, p. 97-110, 1999.

CARNEIRO, L. A. Controle da morfogênese in vitro de três espécies de bromélias endêmicas do Sudeste brasileiro. 1997. 87 f. Tese (Doutorado em Agronomia) - Escola Superior de Agricultura de Luiz de Queiroz, Piracicaba, 1997.

CARVALHO, L. F. N.; COIMBRA, G. C. Experiências com fertilizantes e substratos para o cultivo de bromélias. Ribeirão Preto: [s.n.], 1995. Mimeo. 
DICKSONIA-SELLOWIANA. Dicksonia sellowiana. Disponível em: <http://www.mma.gov.br/cgmi/institu/ pesquisas/pesquisas.cfm>. Acesso em: 25 jul. 2005.

FAQUIN, V. Nutrição mineral de plantas. Lavras: UFLA/ FAEPE, 2001.

FERREIRA, D. F. SISVAR. Versão 4.3. Lavras: UFLA/DEX, 1999. 4 disquetes.

GATTI, A. C. Cultura de tecidos em plantas ornamentais: manual de floricultura. In: SIMPÓSIO BRASILEIRO DE FLORICULTURA E PLANTAS ORNAMENTAIS, 1992, Maringá, PR. Anais... Maringá: UFPR, 1992. p. 28-35.

GONÇALVES, A. L. Características de substratos: manual de floricultura. In: SIMPÓSIO BRASILEIRO DE FLORICULTURA E PLANTAS ORNAMENTAIS, 1992, Maringá, PR. Anais... Maringá: UFPR, 1992. p. 44-52.

KAMPF, A. N. Substratos para floricultura: manual de floricultura. In: SIMPÓSIO BRASILEIRO DE FLORICULTURA E PLANTAS ORNAMENTAIS, 1992, Maringá. Anais... Maringá: UFPR, 1992. p. 36-43.

KOZAI, T. Acclimatization of micropropagated plants. In: BAJAJ, Y. P. S. (Ed.). Biotechnology in agriculture and forestry 17: high-tech and micropropagation I. Berlim: Springer Verlag, 1991. p. 127-141.

LIVRAMENTO, D. E. do; ALVES, J. D.; BARTHOLO, G. F.; GUIMARÃES, P. T. G.; MAGALHÃES, M. M.; PEREIRA, T. A. Efeito da pulverização de solução de sacarose na produtividade de cafeeiros (Coffea arábica L). In: SIMPÓSIO DE PESQUISA DOS CAFÉS DE BRASIL, 3., 2003, Viçosa, MG. Anais... Viçosa: UFV, 2003. p. 286.

MALAVOLTA, E. Elementos da nutrição mineral de plantas. Piracicaba: CERES, 1980. 251 p.

MENDONÇA, P. G. Estimativa da área foliar de Tillandsia spp. (Bromeliaceae) e similaridade entre espécies com base em dimensões foliares. 2002. 86 f. Dissertação
(Mestrado em Genética e Melhoramento de Plantas) Universidade Estadual Paulista, Jaboticabal, 2002.

MERCIER, H.; KERBAUY, G. B. In vitro culture of Vriesia hieroglyphica, of endangered bromeliad from the Brasilian Atlantic Forest. Journal Bromeliad Society, [S.1.], v. 44, p. 120-124, 1994.

PASQUAL, M. et al. Cultura de tecidos vegetais: tecnologia e aplicações: introdução: fundamentos básicos. Lavras: UFLA/FAEPE, 1997. 159 p.

RAUTH, W. The bromeliad lexicon. London: Blondford, 1990.

RODRIGUES, T. M. Substratos e adubação na aclimatização e desenvolvimento inicial de mudas de bromélia imperial. 2003. 62 p. Dissertação (Mestrado em Fitotecnia) Universidade Federal de Lavras, Lavras, 2003.

SILVA, J. C. da; ALVES, J. D.; ALVARENGA, A. A. de; MAGALHÃES, M. M.; CARNEIRO, L. F. Efeito da aplicação de açúcar no teor e no metabolismo de carboidratos em plantas de café com diferentes níveis de reservas de carbono. In: SIMPÓSIO DE PESQUISA DOS CAFÉS DO BRASIL, 2000, Viçosa. Anais... Viçosa: UFV, 2000. p. 108-111.

SPURR, S. H.; BARNES, B. Y. Forest ecology. New York: The Ronald, 1973. 571 p.

SPURR, S. H. et al. The bromeliad society. Arcadia: Kerr, 1977.

WALL, B. Some pH chances in nutrient solucions. Bot Gaz, [S.1.], v. 110, p. 605-613, 1988.

TAKEYOSHI, N. I.; ANRAKU, R. N.; MINAMI, K.; LIMA, A. M. L. P. Efeito de diversos substratos no enzaizamento de Chrysanthemum morifolium cv. Polaris. In: CONGRESSO BRASILEIRO DE FLORICULTURA E PLANTAS ORNAMENTAIS, 2., 1983, Rio de Janeiro, RJ. Anais... Rio de Janeiro: Embrapa-DDT, 1984. 280 p. 